\title{
INTESTINAL OBSTRUCTION DUE TO A FORGOTTEN MISSING LIPPES LOOP- A CASE REPORT WITH REVIEW OF LITERATURE
}

Mohan Joshi' ${ }^{1}$ Ashwini Paranjpe², Vishwajeet Pawar 3 , Monika Pohekar ${ }^{4}$, Devbrata Adhikari ${ }^{5}$

1 Professor and HOD, Department of Surgery, Lokmanya Tilak Municipal General Hospital, Mumbai, Maharashtra.

${ }^{2}$ Senior Registrar, Department of Surgery, Lokmanya Tilak Municipal General Hospital, Mumbai, Maharashtra.

${ }_{3}^{3}$ Assistant Professor, Department of Surgery, Lokmanya Tilak Municipal General Hospital, Mumbai, Maharashtra.

${ }^{4}$ Resident, Department of Surgery, Lokmanya Tilak Municipal General Hospital, Mumbai, Maharashtra.

${ }_{5}^{5}$ Associate Professor, Department of Surgery, Lokmanya Tilak Municipal General Hospital, Mumbai, Maharashtra.

HOW TO CITE THIS ARTICLE: Joshi M, Paranjpe A, Pawar V, et al. Intestinal obstruction due to a forgotten missing Lippes loop- a case report with review of literature. J. Evolution Med. Dent. Sci. 2018;7(21):2649-2650, DOI: 10.14260/jemds/2018/595

\section{PRESENTATION OF CASE}

A 45-year-old female patient presented with intermittent pain in abdomen and recurrent episodes of vomiting since 6 months. She also reported intermittent constipation. On examination, patient had tachycardia of $120 / \mathrm{min}$ and blood pressure of $110 / 70 \mathrm{mmHg}$. Rest of general examination was normal. Per abdomen exam revealed mildly distended abdomen with mild tenderness in periumbilical region. Auscultation revealed hyperperistalsis of the bowel. Plain radiographs revealed dilated small bowel loops with air fluid levels. Abdominal ultrasound was equivocal. CT scan revealed transition zone in mid-ileal region with delayed to no passage of oral contrast beyond it. Conservative management was initiated with proximal decompression with a nasogastric tube. Patient continued to have tachycardia and abdominal pain. Endoscopy was done. Decision was taken to perform exploratory laparotomy. Intra-abdominal findings were dilated jejunal and proximal ileal loops. Distal ileal loops were clumped and rotated around a foreign body. On further dissection, an entangled Lippes loop (a double S shaped intrauterine device) was identified forming a foreign body granuloma. Lippes loop was extracted and bowel was reposited. Postoperative recovery was unremarkable. Patient reported of relief of symptoms. This is a rare case of a forgotten Lippes loop, which caused silent perforation of the uterine wall and migrated intraperitoneally to cause intestinal obstruction. On thorough review of literature, there are instances documented of a forgotten missing Lippes loop causing complications and ours appears to be only one of the few to report a case of intestinal obstruction.

\section{DIFFERENTIAL DIAGNOSES}

- Acute intestinal obstruction.

- Acute pancreatitis.

\section{CLINICAL DIAGNOSIS}

Acute intestinal obstruction.

\section{PATHOLOGICAL DISCUSSION}

Torsion of mesentery and small bowel around a foreign body granuloma.

\section{'Financial or Other Competing Interest': None.}

Submission 12-04-2018, Peer Review 05-05-2018,

Acceptance 12-05-2018, Published 21-05-2018.

Corresponding Author:

Mohan Joshi,

Professor and HOD, Department of Surgery,

Lokmanya Tilak Municipal General Hospital,

Mumbai, Maharashtra.

E-mail:mohansion@gmail.com

DOI: $10.14260 /$ jemds/2018/595

\section{(c) (i) $(9)$}

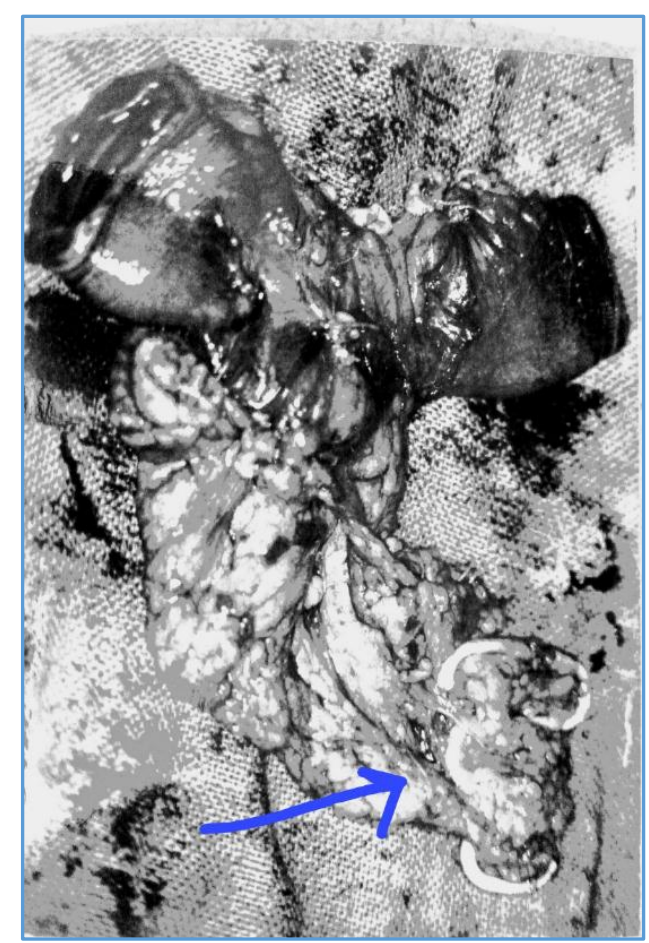

Lippes Loop

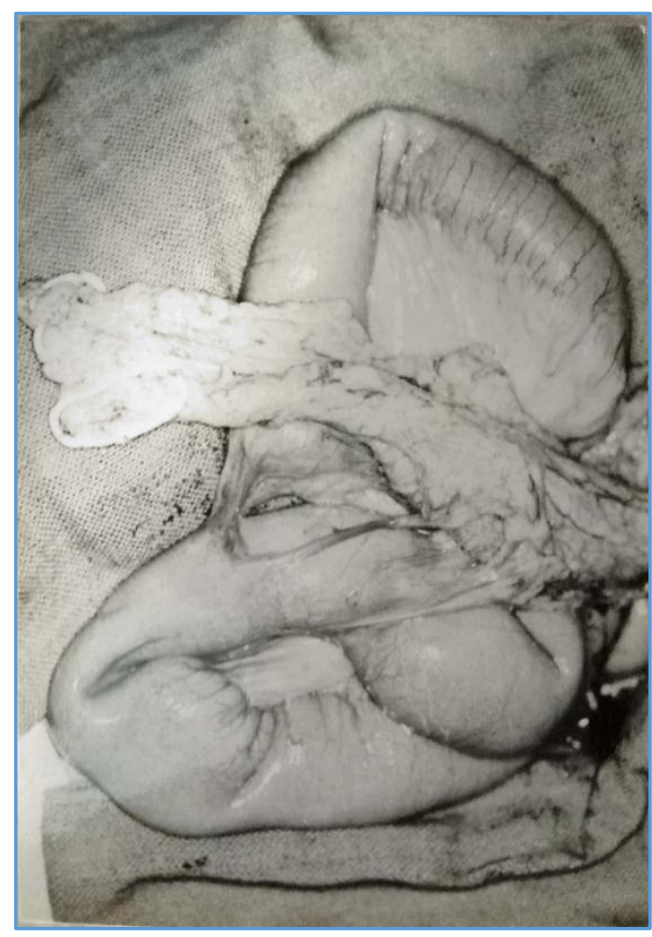

Segment of Intestine Loop Resected 


\section{DISCUSSION}

Cases have been reported in literature of prolonged use of IUD.(1,2) The time period of retained uterine devices varied from 22 to 44 years. Most common presentation was postmenopausal bleeding.(1,2)

Cases of silent perforation of LL-IUD with asymptomatic migration have been reported. Spontaneous perforation is a rare, but well known complication of IUD insertion where the IUD initially embeds in the uterine wall followed by complete perforation to thus migrate in the peritoneal cavity. Inert IUD like Lippes Loop tend to remain asymptomatic for years and are often discovered incidentally during the investigative work-up for some other disease. $(3,4,5)$ Ours appears to be a rare case of silent perforation presenting with intestinal obstruction.

Rosita Aniulienè reported a case of a patient inserted with a Lippes loop who had forgotten it for 50 years. The LL was incidentally found in the uterine cavity and extracted eventually. It caused no symptoms for 50 years.(2)

Phupong $\mathrm{V}$ et al reported a case of a uterine perforation due to Lippes loop IUD-associated actinomycotic infection. The LL was inserted almost 35 years ago, which was forgotten.(6) There have been cases reported of abdominal wall actinomycosis secondary to LL retained in the uterus. $(6,7)$

Several interesting studies and rare case reports of complications following insertion of Lippes loop discussed subsequently, which tilts the balance heavily in favour of removal of a Lippes loop- Intrauterine device irrespective of it causing no difficulty or symptoms to the patient and it goes without saying that it is mandatorily removed in the event of any discomfort or symptom to the patient.(3)

\section{FINAL DIAGNOSIS}

Acute intestinal obstruction due to a forgotten missing Lippes loop.

\section{REFERENCES}

[1] Pisal N, Mammo M. Case-series report: management of post-menopausal bleeding in the presence of an intrauterine device. Contraception 2002;66(5):383-4.

[2] Aniulienė R, Aniulis P. Lippes Loop intrauterine device left in the uterus for 50 years: case report. BMC Women's Health 2014;14:97.

[3] Sinha M, Rani R, Gupta R, et al. Lippes Loop inserted 45 years back: the dilemma to remove it or leave it in situ. A case report with review of literature. Journal of Clinical and Diagnostic Research: JCDR 2015;9(4):QE01-5.

[4] Tsafrir A, Plotkin V. One intrauterine device lost, two found. Fertil Steril 2008;90(1):185.

[5] Harrison RF. Adenocarcinoma of the uterine body following use of intrauterine contraceptive device. Ir J Med Sci 1971;140(9):407-9.

[6] Phupong V, Sueblinvong T, Pruksananonda K, et al. Uterine perforation with Lippes loop intrauterine device-associated actinomycosis: a case report and review of the literature. Contraception 2000;61(5):347-50.

[7] Lunca S, Bouras G, Romedea NS, et al. Abdominal wall actinomycosis associated with prolonged use of an intrauterine device: a case report and review of the literature. Int Surg 2005;90(4):236-40. 